\title{
The writing's on the wall for Sherlock
}

\author{
(1) (1) $($ OP OPEN ACCESS \\ Thomas Ruder and colleagues discover that once again the sleuth's hunches were right
}

\author{
Thomas D Ruder attending physician and researcher ${ }^{12}$, Yannick Thali research assistant ${ }^{2}$, Matthias \\ Bucher statistician ${ }^{1}$, Annie Cottier assistant and PhD student ${ }^{3}$, Michael J Thali director ${ }^{1}$, Gary M \\ Hatch attending physician and researcher ${ }^{4}$
}

${ }^{1}$ Institute of Forensic Medicine, University of Zurich, Winterthurerstrasse 190/52, CH-8057 Zurich, Switzerland; ${ }^{2}$ Institute of Forensic Medicine, University of Bern, Bern, Switzerland; ${ }^{3}$ English Department, University of Bern, Bern, Switzerland; ${ }^{4}$ Office of the Medical Investigator, University of New Mexico, Albuquerque, NM, USA

"There has been murder done, and the murderer was ... more than six feet high"1

In Sir Arthur Conan Doyle's A Study in Scarlet, Sherlock Holmes and his companion Dr John Watson find themselves at the scene of a homicide: a man's body has been discovered in an abandoned house, with the word RACHE (German for revenge) written in blood on a nearby wall. Holmes reads footprints in the dust, scrutinises little heaps of tobacco ash with his magnifying glass, and takes a close look at the bloody inscription. Based on his observations he states:

"[T]he murderer . . . was more than six feet high.",

Flattered by Watson's amazement, Holmes explains:

"[T] he height of a man ... can be told from the length of his stride [and] I had this fellow's stride both on the clay outside and on the dust within."1

With this knowledge, Holmes was ahead of his time: it was not until the late 20th century that a group of forensic scientists rediscovered the correlation between height and stride. ${ }^{23}$ However, they found that the length of a stride depends not only on someone's height but also on walking speed. ${ }^{3}$ Holmes, of course, knew about the limitations of his method and applied a second technique to confirm his estimation: "When a man writes on a wall, his instinct leads him to write about the level of his own eyes. Now that writing was just over six feet from the ground. It was child's play."1

In true Holmesian fashion we set out to determine whether there is a correlation between writing level, eye level, and height. Does instinct really lead people to write about the level of their own eyes, and can a writer's height be calculated from an inscription on a wall?

\section{The science of deduction Measurements}

Each of 100 volunteers (46 men, 54 women), aged 19-66, was asked to write the word RACHE on a large glass window using a non-permanent marker (Whiteboard Marker 1741 Velleda, Bic, Clichy, France). The study supervisor used a standard retractable tape measure (Lux Basic, Lux-Tools, Wermelskirchen, Germany) to record the height of the writing (to the centre of the first letter), the font size (height of the first letter), and the volunteer's height and eye level. Measurements were rounded up or down to the nearest centimetre. At the end of the experiment, the study supervisor cleaned the inscriptions off the window. No windows were permanently blemished during this study.

We used statistical software (SPSS 17.0, IBM, Chicago, USA) to assess the normality of distribution of all variables and to calculate correlation coefficients and significance levels. P values less than 0.05 were considered significant.

\section{Results}

The volunteers' mean height was 175.1 (SD 8.9) cm, mean eye level was 164.1 (SD 8.3) cm, and mean writing level on the wall was $163.3($ SD 7.5$) \mathrm{cm}$ )-less than $1 \mathrm{~cm}$ below eye level (mean difference $0.7(\mathrm{SD} 7.0) \mathrm{cm}$ ). Font size ranged from $3 \mathrm{~cm}$ to $33 \mathrm{~cm}$ (mean 8.5 (SD 4.0$) \mathrm{cm}$ ).

A strong correlation was found between the volunteers' height and both eye $(r=0.99, \mathrm{P}<0.001)$ and writing level $(r=0.58$, $\mathrm{P}<0.001)$ as well as between writing level and eye level $(\mathrm{r}=0.61$, 
$\mathrm{P}<0.001$ ). A scatter plot depicts these relations (figure $\Downarrow$ ). The interaction of the regression lines illustrates an additional finding, that shorter than average volunteers showed a tendency to write above eye level and taller than average volunteers to write below eye level.

Font size was unrelated to the other variables and did not correlate with body height $(\mathrm{r}=0.00)$, eye level $(\mathrm{r}=0.00)$, or writing level $(\mathrm{r}=0.24)$.

\section{Elementary, my dear reader Discussion}

This study confirms Sherlock Holmes's theory that people who write on walls instinctively write about eye level. In our population, mean eye and writing levels were almost equal. Additionally, we found that volunteers who were shorter than the average tended to write above eye level, whereas those who were taller than average wrote below eye level. The difference between short and tall volunteers was probably caused by a lifelong adaptation - that is, shorter people are used to looking upwards therefore their visual comfort zone is above eye level, whereas the opposite applies to tall people.

Finally, Holmes's estimation that the suspect in A Study in Scarlet must be "more than six feet high" because "[his] writing was just over six feet from the ground" was also confirmed in our study: the only volunteer who wrote more than six feet above the ground was indeed over six feet tall.

\section{Practical use: the long and the short of it}

Nevertheless, Holmes's method is of little practical use for criminal profiling. Based on our linear regression analysis, the height of someone leaving an inscription at $164 \mathrm{~cm}$ can range from $144 \mathrm{~cm}$ to $207 \mathrm{~cm}$. Even if the confidence interval is lowered from $95 \%$ to $50 \%$, the range can only be narrowed down to about $20 \mathrm{~cm}(166 \mathrm{~cm}$ to $187 \mathrm{~cm})$, which still spans most western European adults. Despite these obvious limitations, a French police detective reportedly applied this technique to arrest the supposed authors of various graffiti in Lyon in the late 19 th century. ${ }^{4}$

Interestingly, in some editions of A Study in Scarlet, the phrase "about the level of his own eyes"1 appears as "above the level of his own eyes." This alternative version is clearly not supported by our data. To identify the original version, two coauthors of this study went to the British Library in London where the first edition of $A$ Study in Scarlet is archived. One of the coauthors was allowed to consult a facsimile of Beeton's Christmas Annual, in which the novel was first published in $1887,{ }^{6}$ as well as a facsimile of the first edition of the book of A Study in Scarlet. ${ }^{7}$ Access to the original manuscripts was unfortunately denied. Nevertheless, the investigation revealed that "about the level of his own eyes" was used in the original version. It remains unclear if the alternative version is the result of a misprint or part of the common linguistic and textual modifications in American editions of the Sherlock Holmes stories. ${ }^{5}$ Finally, we cannot exclude the possibility that an unusually short book editor adapted the phrase based on his or her personal experience.

A few limitations of this study deserve comment. Firstly, in the original Sherlock Holmes's story the murderer wrote on a brick wall, whereas in our experiment the volunteers used a glass wall (or window). The main reason for this was that inscriptions made by board markers can be easily washed off windows but not off brick walls. Secondly, the study supervisor (height 187 $\mathrm{cm}$ ) may have introduced bias by his presence during the experiment and caused the shorter volunteers to subconsciously elevate their writing level to that of the supervisor's eye level $(174 \mathrm{~cm})$. The authors hope to investigate this effect in a future study.

\section{"It was child's play"}

Our results reinforce the popular opinion that the Sherlock Holmes stories are not only elementary to the genre of crime fiction but also to the discipline of forensic medicine.

Nevertheless, we acknowledge that our work will have little impact on forensic profiling methods and that our investigations may be concluded with Holmes's own words: "It was child's play."

Competing interests: All authors have completed the ICMJE uniform disclosure form at www.icmje.org/coi_disclosure.pdf (available on request from the corresponding author) and declare: no support from any organisation for the submitted work; no financial relationships with any organisations that might have an interest in the submitted work in the previous three years; and no other relationships or activities that could appear to have influenced the submitted work.

Provenance and peer review: Not commissioned; externally peer reviewed.

Conan Doyle A. A study in scarlet. Penguin Classics, 2001.

2 Jasuja OP, Manjula. Estimation of stature from footstep length. Forensic Sci Int 1993;61:1-5.

3 Jasuja OP, Harbhajan S, Anupama K. Estimation of stature from stride length while walking fast. Forensic Sci Int 1997:86:181-6.

4 Wagner JE. The Science of Sherlock Holmes: from Baskerville Hall to the valley of fear, the real forensics behind the great detective's greatest cases. Wiley, 2006.

$5 \quad$ Klinger LS. The new annotated Sherlock Holmes: the novels (a study in scarlet, the sign of four, the hound of the Baskervilles, the valley of fear). Norton, 2005.

6 Conan Doyle A. A study in scarlet. In: Beeton's Christmas annual. Ward, Lock, 1887, facsimile ed, No $447 / 550$.

7 Conan Doyle A. A study in scarlet. Ward, Lock, 1888, facsimile ed, 1987.

\section{Cite this as: BMJ 2011;343:d7406}

This is an open-access article distributed under the terms of the Creative Commons Attribution Non-commercial License, which permits use, distribution, and reproduction in any medium, provided the original work is properly cited, the use is non commercial and is otherwise in compliance with the license. See: http://creativecommons.org/licenses/by$\mathrm{nc} / 2.0 /$ and http://creativecommons.org/licenses/by-nc/2.0/legalcode. 


\section{Figures}

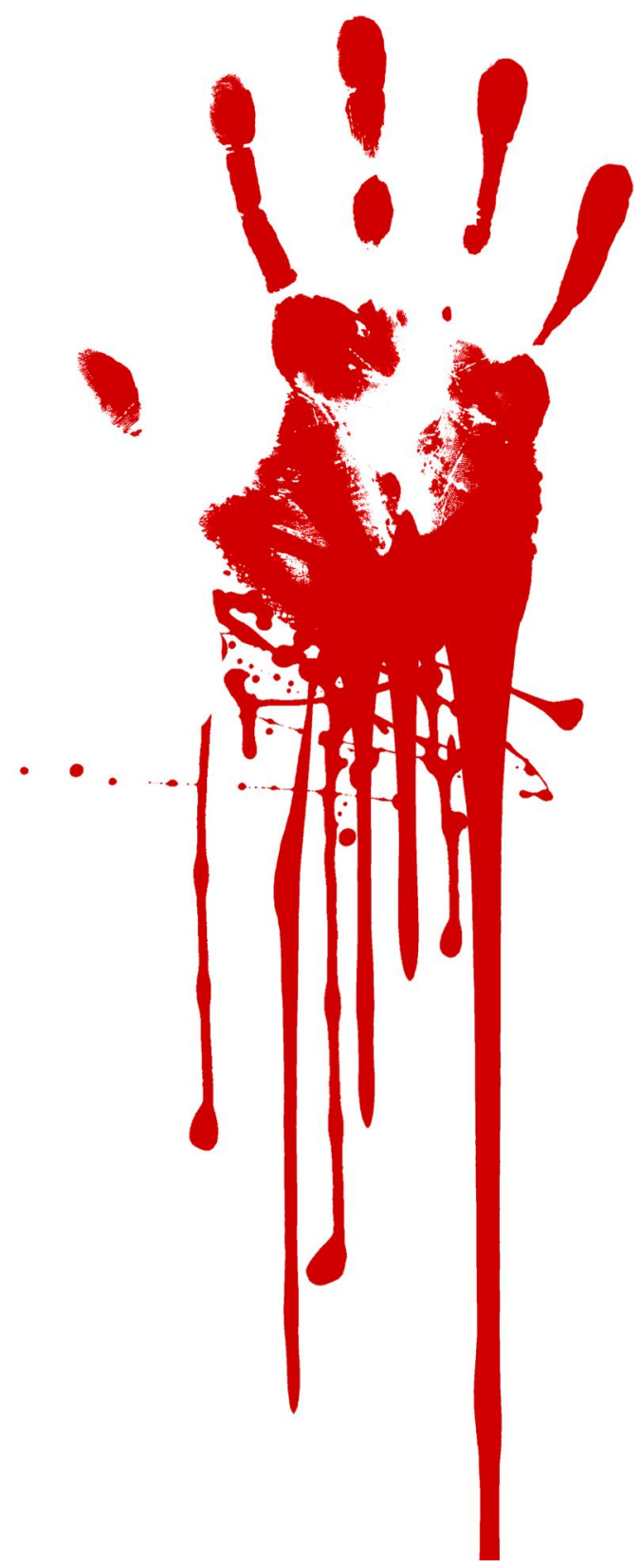


BMJ 2011;343:d7406 dol: 10.1136/bmj.d7406 (Published 20 December 2011)

Page 4 of 5

FEATURE

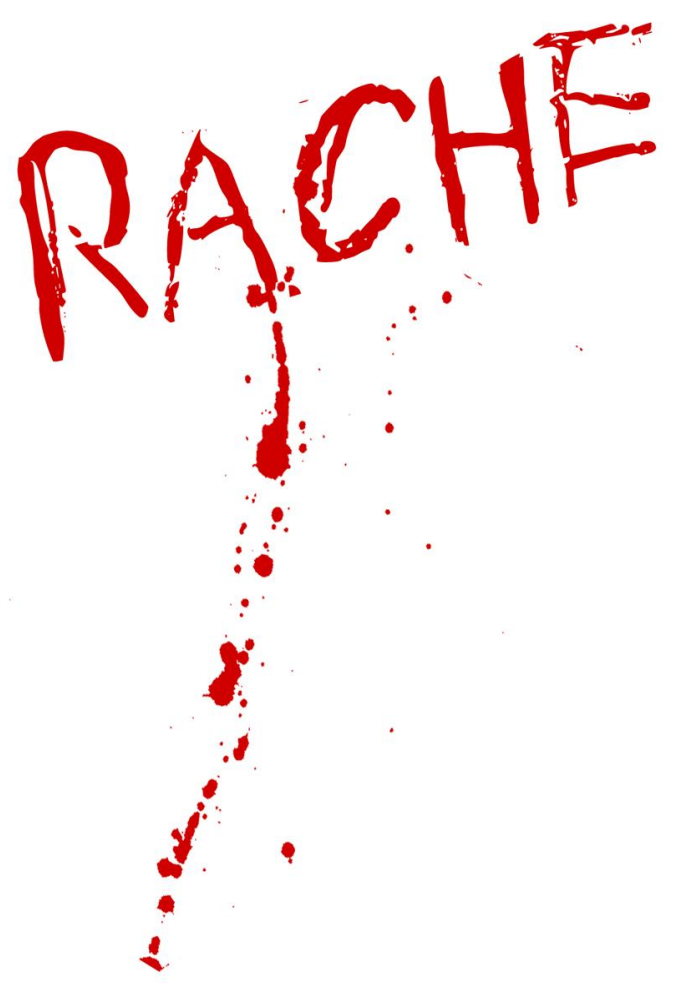

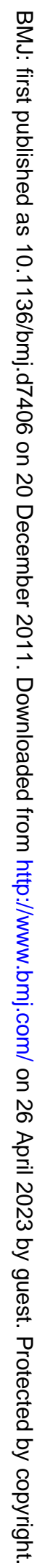

[Image: Jennifer Doneske, www.coverstorystudios.com]

No commercial reuse: See rights and reprints http://www.bmj.com/permissions

Subscribe: http://www.bmj.com/subscribe 


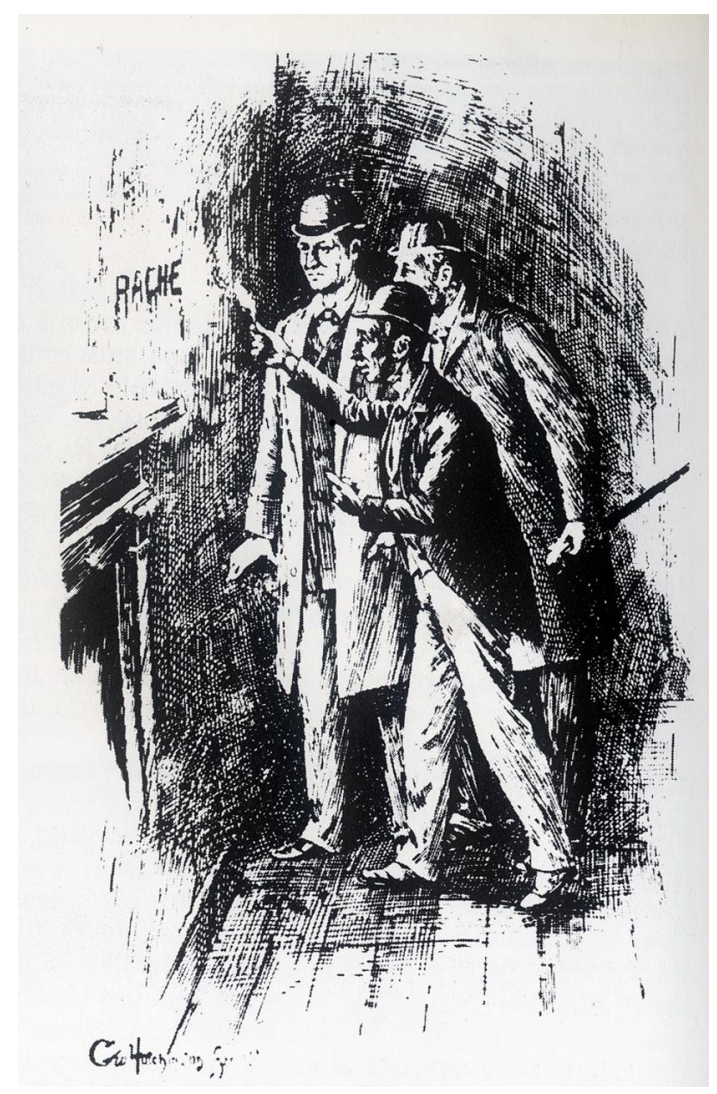

